\title{
Emotions and Distrust in Science
}

\author{
Katherine Furman \\ Department of Philosophy, University of Liverpool, UK \\ katherine.furman@liverpool.ac.uk
}

Keywords: Distrust in science, affective distrust, emotions, objectivity, values in science

\begin{abstract}
In our interactions with science we are often vulnerable; we don't have complete control of the situation and there is a risk that we, or those we love, might be harmed. This is not an emotionally neutral experience. There has been an outpouring of philosophical literature on trust in science as the consequences of distrust become clear. This has exclusively focussed on epistemic and value-based dimensions of trust. In this paper I advocate for taking the emotional aspects of distrust in science seriously.
\end{abstract}

\section{Introduction}

When we hand over our children for vaccination, we trust not only the doctor or nurse in front of us, but the whole scientific enterprise underpinning the vaccination programme. In these moments we are vulnerable. We don't have complete control of the situation and there is risk of harm, either to ourselves or to those we love. Trust is important for these interactions and allows them to occur. Annette Baier (1986) describes trust in terms of this experience of vulnerability:

Where one depends on another's good will, one is necessarily vulnerable to the limits of that good will. One leaves others an opportunity to harm one when one trusts, and also shows one's confidence that they will not take it... Trust then, on this first approximation, is accepted vulnerability to another's possible but not expected ill will (or lack of good will) toward one (Baier 1986, 235).

This experience of vulnerability and the recognition of potential harm is not emotionally neutral. Rather, it feels a certain way.

In recent years, there has been an outpouring of philosophical literature on public trust in science as the consequences of distrust become clear. Distrust in medical science results in parents failing to vaccinate their children and the return of diseases previously thought eradicated. Distrust in climate science leads to lack of public support for urgent climate change mitigation policies. However, almost all of this philosophical literature has focussed 
on epistemic dimensions of trust (Oreskes 2019, John 2011, 2017, Grasswick 2010, Scheman 2001). Some has focussed on values (Kitcher 2011, De Melo-Martin and Intemann 2018, Goldenberg 2016). None has focussed on the affective dimensions of trust and distrust in science. When we exclude emotion, we miss aspects of the phenomenon, which limits our ability to understand and intervene in these important areas.

In this paper I argue that philosophical accounts of trust and distrust in science should include emotions. That is not to disregard epistemic and value-based considerations, which are both clearly important. Rather, my aim in this paper is modest; it is just to argue that we should pay closer attention to emotions when trying to understand distrust in science. To that end, this paper is structured in the following way. In Section 2, I outline the ways in which philosophers of science currently write about trust and distrust in science, noting that this literature is directed toward epistemic and value-based considerations. In Section 3, I discuss the examples of early HIV/AIDS interventions in South Africa and Ebola interventions in West Africa. These are cases in which people distrusted the interventions and part of the motivation for that distrust was emotional. In section 4, I draw out some implications of taking emotions seriously when trying to understand distrust in science. Finally, in section 5 I propose a way of understanding the interaction between rationality, values and emotions when understanding public trust and distrust in science; which is that they are all important and which is most salient in any particular situation is context dependent.

Before proceeding, it should be noted that when I use the term "science" I don't just mean the set of propositions and theories produced by bench-scientists. I also mean the products of science, such a vaccines, dam construction (to borrow an example from Pierliugi Barrotta and Eleonora Montuschi $(2018,391)$ ) and genetically modified foods (to borrow an example from Justin Biddle (2018)). I also mean the various government directed interventions by which the products of science are delivered to the public; such as vaccination programmes, public consultations that help decide where the dam will be built, and the policy decisions that result in GMO foods becoming available in our supermarkets. The interactions that most of us have with science are not with the white coats in labs or their peer-reviewed papers, but rather with dams, vaccinations and food. And it is these interactions that can make or break our trust with the whole scientific endeavour. Think about the impact that the Thalidomide case had on public trust in science, which was as much about pharmaceutical regulation (the realm of policy and government) and prescription (the realm of medical practitioners) as it was about the laboratory science.

Another note before proceeding is that my emphasis throughout this paper will be on distrust rather than trust. This is because the cases become more interesting and socially relevant when trust breaks down.

\section{Current philosophical discussions of trust/distrust in science}


In this section I provide an overview of the way philosophers of science write about trust. This list is indicative, not exhaustive. The examples are chosen because they help our understanding of either normative or descriptive aspects of the phenomenon. My intention is not to cherry pick pieces of the literature to support my point, but rather to give the reader a sense of the intellectual landscape in which we are operating. I start by discussing epistemic accounts in 2.1 and then move on to values-based accounts in 2.2 .

\subsection{Epistemic Trust and Distrust}

Much recent philosophical literature on trust and distrust in science has focussed on epistemic considerations. A popular way of doing this has been to point to elements of scientific practice that make it more trustworthy. Naomi Oreskes in Why Trust Science (2019), argues that science is trustworthy because of its collective nature. For Oreskes, like Helen Longino in Science as Social Knowledge (1990), it is the checks provided by the scientific community - the rigorous debate, the peer review - that make the results of scientific enquiry more likely true and thus more worthy of our trust. Similar reasoning is appealed to in discussions very closely related to trust, such as deference to experts (Jones 2002) and scientific objectivity (Koskinen 2018).

Reiss and Sprenger (2017) claim that one of best things about science is objectivity. And one of the best things about scientific objectivity is its ability to secure trust - an objective science is a trustworthy science (Fine 1998, Douglas 2004, Scheman 2001, Grasswick 2010). Inkeri Koskinen (2018) is one such writer who focusses on the scientific procedures discussed above to generate objectivity. Her account focusses on epistemic risk management. An important part of scientific practice is having procedures that ensure epistemic errors don't creep in, and it is these procedures that make science objective. However, for Koskinen, objectivity isn't about "trust". Rather, she argues that much of the language of trust in science should be replaced by that of "reliance" (Koskinen 2018, 6). Trust is something that can be "betrayed". It is an ethically richer concept, governing our relationships with other human beings. Reliance is an ethically thinner notion, explicitly detached from emotion and reactive attitudes (John 2020, 50). Koskinen's point is that the thinner notion of reliance better captures our relationship to science, rather than the rich interpersonal relationships that require trust. My relationship to science it more like my relationship to my car, which I rely on and I am let down when it stops working, but I am never betrayed by my car. Betrayal is for lovers, not for cars or science (John 2020, 50).

Even when the philosophical literature adopts a more interpersonal stance, focussing on the sense of vulnerability and the marginalisation that can give rise to distrust in science, the emphasis is still typically epistemic. Grasswick (2010) and Scheman (2001) both discuss the example of the introduction of the contraceptive pill in African American communities in the 
United States. This was met with distrust, which was rational given the long history of abuse experienced by African Americans at the hands of the medical establishment. If someone has betrayed your trust in the past, or the trust of those similar to you, they might do so again and so it is rational to distrust them in future interactions (Grasswick 2010, 390; Scheman 2001, 43).

In a very different kind of philosophical discussion of epistemic distrust in science, Stephen John in Expert Testimony and Epistemological Free-Riding (2011) provides a rational reconstruction of the MMR (Measles, Mumps, Rubella) vaccine case. He postulates that those who do not vaccinate their children can be described as hyper-rational. If you are uncertain about whether it is safe to vaccinate your children, the individually rational thing to do is not to vaccinate. This allows you to avoid risk to your own child, while benefitting from the herd immunity if everyone else vaccinates.

However, paying attention to only epistemic trust cannot be right, where 'epistemic trust' is about rational acceptance of claims from relevant experts (John 2020, 51). Our concern about whether laypeople trust science isn't just about whether they accept or believe the claims of science. Rather, we are worried about whether these claims translate into action. Grasswick (2010), for instance suggests, that part of the reason we are bothered at all about relationships between scientists and laypeople is because many of the aims of science require public participation to succeed - there is no point in developing a vaccine and a related public health programme if nobody brings their children to be vaccinated, and this requires trust (393). However, the link between belief and action isn't always straightforward (Arpaly 2004). Rather, we need something more than epistemic trust to achieve the desirable social outcomes that worry us - successful vaccination programmes, well-supported climate policies, public willingness to wear masks and socially-distance during epidemics, etc.

\subsection{Values-based Trust and Distrust}

A potentially useful supplement to our philosophical discussions of epistemic trust in science are the values-based accounts that some have adopted. What counts as a "value" in this literature is notoriously under-theorised (Brown 2018, 6). For our purposes, it is enough to say that values are those things that we care about.

Philip Kitcher in Science in a Democratic Society (2011) argues that erosion in scientific authority can occur when there are 'opaque value judgments', by which he means that values have been used in the production of science that run counter to those that would be chosen via a democratic process $(162-163)$. The solution on Kitcher's account is thus more democratic participation in science, so that the public can be involved in the choice of values that inform science. 
Maya Goldenberg (2016) has a similar stance, in that she is also concerned with the opacity of values and has advocated for drawing the public in for more productive discussions about values. She is explicitly concerned with the example of vaccine hesitant parents - that is, those who are uncertain about whether to vaccine their children. In particular, Goldenberg is worried about explanations of vaccine hesitancy that rest on descriptions of parents as ignorant about the science and which miss an important part of the picture, which is about value differences. Medical practitioners provide population level explanations of the safety of vaccines, while parents want to know about the safety for their own particular children. She thus advocates for earlier and more authentic communication between lay-people and experts (Goldenberg 2016, 570).

Inmaculada de Melo-Martin and Kristen Intemann (2018) accept that trust is a complicated phenomenon and that multiple factors are likely involved in whether the public trust or distrust science. And interestingly, they suggest that more empirical research is needed on whether values do actually play a role in public trust in science, because most of this discussion is based on philosophical speculation (125). But like Kitcher and Goldenberg, they also argue that certain value-based measures be taken to improve relationships between scientists and the public. Again, these include increased opportunities for public participation in determining the values that are used in science and enhanced valuetransparency (De Melo-Martin and Intemann 2018, 126-127).

Values are a promising place to pay attention to better understand public distrust in science, because they capture some classic cases of distrust in medical science, where sexist, racist and homophobic values eroded trust (Epstein 1996, 2007). The infamous Tuskegee Experiment, which involved intentionally deceiving and not treating black patients with syphilis over a forty-year period was explicitly premised on racist values and has contributed substantially to medical distrust amongst African American communities (Jones 1981, Thomas and Quinn 1991). Values are important. However, in the following section I will discuss some examples that make clear that paying attention to emotions is also required.

\section{Some examples}

Many of the examples that bring the emotional elements of our relationships with science into clearest focus are medical. This is because medicine is one area of science that gets into the most intimate and vulnerable portions of our lives - when we are unwell, when we are dying, when we give birth. This is unlike many other areas of science, like theoretical physics, that are more distant. There are also likely to be examples from environmental science that have the same quality, especially for those whose lives and livelihoods are closely tied to nature and who are thus vulnerable to external intervention, be it corporate or scientific (Kimmerer 2013, Tsing 2015). However, I am more familiar with the medical 
cases and in this section I discuss two examples to show the role of emotions. The first example is that of HIV/AIDS treatment in South Africa in the early 2000s, the second is the recent West African Ebola outbreak.

\subsection{South Africa}

South Africans had a long battle to receive ARVs (anti-retrovirals - the medication needed for those with HIV/AIDS) via the public health system, during which time conservative estimates suggest that there were 171,000 avoidable new HIV infections and 343,000 deaths (Nattrass 2008). Victory was ultimately achieved, mostly through a series of legal cases, and in 2004 the South African Department of Health began rolling out an ARV treatment programme (Gumede 2005). However, this was initially met with mistrust and suspicion, and people resisted both testing and treatment (Steinberg 2009, Fassin 2007). This was a disastrous outcome, given the loss of human life and the protracted battle to make medication publicly available.

Fassin (2007), in his extended anthropological study of the early days of South African HIV/AIDS treatment, When Bodies Remember, argues that what motivated mistrust in this case was what he calls "economies of resentment" and "economies of suspicion"(Fassin 2007,270 - 271). Part of this - the suspicion part - is closely related to epistemic distrust, the same as that described by Scheman (2001) and Grasswick (2010), and discussed earlier in this paper. According to Scheman (2001) and Grasswick (2010), African American women were rationally suspicious of the introduction of the contraceptive pill in their communities, because of the long history of medical abuse experienced by black Americans. In the South African case, racist medical science on hygiene and illness was used to legitimise racial segregation, forced removals and ultimately apartheid. This rationalises South Africans' suspicion toward medical science (Fassin 2007, 270-271).

On Fassin's account, however, the long history of medical abuse doesn't just contribute to epistemic distrust. It also has an emotional component, which is what he describes as 'economies of resentment'. In Fassin's words: "They relive and feel anew the past of violence, humiliation, and loss of dignity that they experienced themselves or experienced through the accounts of parents and relatives" (Fassin 2007, 171). Just like more interpersonal experiences of abuse and trauma, we wouldn't expect survivors to be just rationally suspicious in future encounters. We would also expect their responses to be emotional.

This case is further affectively laden by the connection of HIV/AIDS to people's sexual lives, which can evoke feelings of shame (Fassin 2007, 271). Further still, HIV/AIDS takes place in the already affectively heightened context of anxiety due to the extreme poverty in which many South Africans live their lives. Fassin, quoting from his fieldnotes, remembers visiting 
emaciated patients in filthy homes with no furniture, relying on neighbours for food (Fassin 2007, 240-242). More will be said in section 4 about the role of already heightened affective states. The lesson to take away at this point is that people's interactions with medical science via public health programmes are not emotionally neutral but may be affectively heightened in various ways.

\subsection{West Africa}

Another important case of distrust in medical science is that of the 2013-2016 Ebola epidemic in West Africa, which took place in Liberia, Sierra Leone, and Guinea (the so-called 'Ebola Triangle'). To date, this is the largest outbreak of Ebola with an estimated 28,646 cases (World Health Organisation, 2016). With it came a large-scale international intervention, which was met with distrust and resistance to varying degrees in all three countries.

In milder cases of distrust in Sierra Leone and Libera, individuals failed to report to treatment centres when displaying symptoms and hid sick relatives when medical teams passed through neighbourhoods and villages looking for the ill. This limited treatment and containment efforts. The most extreme cases of distrust and resistance took place in the Forest Region of Guinea. This involved attacks on clinics and medics, and the removal of access bridges and the felling of trees to block road access to villages in an effort to prevent medical teams from gaining entry. Ultimately, in the most extreme case of violence during this time, eight members of a medical team were murdered when they didn't heed warnings not to enter the village (Fairhead 2016, 9).

Some have argued that distrust in this case is value-based. Fairhead (2016), for example, argues persuasively that the international intervention crossed certain "red lines" of value accommodation that had previously been achieved between western medicine and traditional beliefs (11). For instance, the importance of traditional burials that had previously been respected by hospitals were ignored during the epidemic (Fairhead 2016, 12). Funerals are deeply valued in all three countries and much distrust of external intervention focussed on bodies. Examples of this include rumours that medics were stealing the corpses to be sold on the international organ markets, and secret burials or washing of bodies before burial teams could arrive (Wilkinson and Fairhead 2017, 21-23).

However, given the extremity of the response - the removal of access points to villages (which also cut off villagers themselves from the outside world), the violent attacks, and ultimately murder - it seems that something more was involved than just value disagreements. It also seems that fear was involved. This is consistent with reports from social anthropologists who were in the field at the time (Desclaux, Diop and Doyon 2017). Julian Anoko, an anthropologist who was working in Guinea during the epidemic, reports 
the following testimony from an interviewee: "We are afraid of the disease, but are also afraid of all those who come to us to make us aware of it, track contacts or take away the ill" (Anoko 2014, 11).

At this point, I hope that the reader accepts that emotions can play a role in cases of distrust in science. In Section 4 I will describe some implications of taking emotions into account. In the next section I offer some guidance about what taking emotion into account looks like.

\section{Emotional Distrust in Science}

While philosophers concerned with trust and distrust in science have been silent on the topic of emotion, there has discussion of these issues in other areas of inquiry. In this section I start by providing an outline of these discussions, beginning with philosophical accounts of trust that allow for emotion in a limited way, and then moving on to philosophical and sociological descriptions of trust and distrust that involve emotion more expansively. In 4.1. I go on to describe how these thicker emotional accounts help us think about distrust in science, and in section 4.2. I argue that this allows us to better understand certain aspects of the phenomenon.

Some philosophical accounts of trust and distrust permit emotion via Strawsonian reactive attitudes. These accounts, following Strawson (1962), describe trust as based in normative expectation; I trust you to do or not do something. If that trust is betrayed - perhaps you break my precious glass vase instead of looking after it like I had trusted you to - then I am entitled to have negative reactive attitudes toward you, such as resentment or anger (See Hawley 2019, 13 - 15 for discussions of Holton 1994 and Jones 2004 as examples of this). Faulkner (2007) goes so far as to describe this normatively loaded interpersonal dependence as "affective trust" (881). In Faulkner's words:

When we expect something of someone we hold them to this expectation where to do this... is to be susceptible to certain reactive attitudes if they do not do what is expected... The general reactive attitude at play here is resentment: in affectively trusting $S$ to $\phi$, A will be prone to resentment were $S$ to show no motivation to $\phi$ (Faulkner 2007, 882).

Faulkner describes this as a "thicker" sense of trust, where his contrast are theories of trust that allow for no emotion at all - those in which only rational beliefs matter. However, accounts of trust that allow for emotion only once trust has been betrayed - which is the case with reactive attitudes - permit emotion in a very limited way. What I have in mind is an even thicker notion of affective distrust than that described by Faulkner.

Others also have a thick notion in mind when they think of affective trust and distrust, including moral philosophers (Jones 1995, 2019), and sociologists of science (Engdahl and 
Lidskog 2012). It is worth noting that almost all of this literature is explicit that it is written from the disciplinary fringes. They argue that accounts of trust in their respective areas have been overly rational and that emotion is important to understanding the phenomenon. This gives us a sensible place to start thinking about emotion and distrust in science. In the rest of this section I bring together some points of consistency in this literature in an effort to illustrate an affective account of distrust in science.

\subsection{Introducing Affective Distrust in Science}

The way we perceive those we trust, or distrust is "affectively loaded" (Jones 1995, 4). That is, there is no emotional state that is "trust" per se, rather it is a state that is accompanied by other emotions. Baier (1986) talks about "climates" of trust, which can sensibly be described as the positive kind of affective attitudes that make individuals more or less amenable to trusting (258). Jones (1995) describes trust as an "optimistic attitude" that the person on the receiving end of your trust won't harm you or take advantage of you in your moment of vulnerability (4). Engdahl and Lidskog (2012), in the sociological literature, use similar language, describing it as an "anticipatory attitude" (711-712). In the trusting case, the anticipatory attitude is optimistic. In the case of distrust, the anticipatory attitude is one of anxiety (Baier 1986, 234), fear (Jones 2019, 956, Fassin 2007), frustration (Carman 2020), or perhaps even anger. Which emotion, or combination of emotions, are relevant varies depending on context.

The affective attitude may pre-date the situation in which trust or distrust occurs - such as the South African HIV/AIDS case, where Fassin describes some of his research participants as already being in a state of anxiety, due poverty. In this situation, anxiety pre-dates the testing and treatment programme, but impacts the way that people experience it. Affect may also be created by the intervention itself, such as the fear that people felt when encountering the medics in the Ebola case

One way that the negative affect associated with distrust may be created within the interaction between scientists (or the envoys of science, such as medics) and laypeople is through various asymmetries in these interactions. In Baier's words:

[A]nother crucial variable in trust relations to which so far I have indirectly alluded... is the relative power of the truster and the trusted, and the relative costs to each of a breakdown of their trust relationship. (Baier 1986, 240).

The first asymmetry is that of power. Experts typically enjoy privileged status, both epistemically and otherwise, in their interactions with laypeople (Epstein 1996, 6). As a result, in my capacity as a layperson, I may have few routes of effective engagement either epistemically or in terms value-disagreements - with the experts. Of course, this won't be true for everyone. In Katherine Hawley's How to Be Trustworthy (2019) she is 
explicit that not all cases of trust and distrust occur at the fringes of vulnerability. Hawley's observation can hold true even in relationships between laypeople and members of the scientific community; it is not all vulnerability all the time. For instance, perhaps I am married to a well-known medical malpractice lawyer, with the result that when I go in for pre-natal care and birth plan advice, my epistemic and value-based concerns are accommodated, and I feel nothing but ease and comfort throughout the process. In this situation, emotion isn't hugely relevant to my experience of trust in science and its envoys.

However, in the fictional case of my marriage to a medical malpractice lawyer, the power balance had been shifted in favour of the layperson. Many people aren't in this situation and are on the weaker side of power asymmetries. The cases discussed in this paperHIV/AIDS treatment in South Africa and Ebola interventions in West Africa - involve extreme power asymmetries. One consequence of this may be that the layperson doesn't have avenues through which their epistemic and value-based considerations are heard. There is an extensive pre-existing literature on this, thanks to Miranda Fricker's (2007) work on epistemic injustice. This can be frustrating, anxiety-provoking, anger-inducing. Alison Bailey (2018) evocatively describes the way that having few or no routes to epistemic engagement (the same is likely true for engagement about values) can create anger in the following passage:

Our anger surfaces quickly pulling us back into our bodies... Those of us who live in epistemic twilight zones, in worlds where testimony about our lived experiences is repeatedly silenced, dismissed, distorted or gas lighted are familiar with the everpresent anger these constant erasures trigger (Bailey 2018, 93)

That said, the affective consequences of power asymmetries need not be the death knell for public trust in science. Once we recognise that this can be a feature of the relationships between the public and scientists, especially with very vulnerable and marginalised individuals and groups, we can take measures to do something about it. Going back to the case of early HIV/AIDS treatment in South Africa discussed in Section 3.1, Jonny Steinberg (2016), describes the case of a doctor from MSF (Médecins Sans Frontières - Doctors without Borders) who administered HIV tests, so that those who needed treatment could get it:

The white MSF doctor who spearheaded the programme introduced himself to the local population by traveling from village to village personally conducting voluntary HIV tests. Within weeks, rumors circulated that the doctor was spreading HIV in his needle. It was said that he was an agent of the old apartheid regime; that a conspiracy was in progress to infect so many black people with AIDS that whites would become an electoral majority. In one village, a hostile crowd confronted the doctor with this accusation. The tension only abated when he stood up on a table, drew his own blood in front of the assembled crowd and explained as best he could the science behind the tests that would be done on it (Steinberg 2016, 66-67). 
Steinberg's story is instructive for many reasons. It is a case of a medical intervention that was beneficial to those receiving it, but it was met with mistrust. It is also a situation that was affectively laden - he describes it as "hostile" and "tense". By standing on the table, addressing the crowd, and taking his own blood, the doctor was able to shift the asymmetry a little and thus ease the tension. It is unclear whether just "explaining the science as best he could" would have done the affective work necessary to win over the trust of the hostile crowd, but by taking his own blood he indicates to the crowd that he is willing to take on some of the risk he was asking of them. This gestures toward a second asymmetry.

Related to power symmetries, but not identical to them, are cost asymmetries. Trusting another involves taking on a potential cost in terms of risk. You become dependent on another for at least the thing you are trusting them for, and as a result you are vulnerable to them (Engdahl and Lidskog 2012, 711). The expert is usually not subject to the same potential costs as the layperson. It is my sick relative I contemplate taking to the Ebola treatment centre. It is my baby I hand to the nurse for vaccination. I have 'skin in the game' in ways that they expert doesn't, at least in this interaction. Part of the affective work that the MSF doctor does is that he takes on a little bit of that risk for himself.

Being on the weaker side of these power and cost asymmetries can add to the affective load of the situation, even If there wasn't one before. Because it can make you feel anxious, fearful, frustrated, angry. And these emotions make the climate not particularly amenable to trust.

\subsection{Implications of Emotions for Distrust in Science}

In 4.1 we gained a sense of the emotional elements of distrust in science. In this section I show that once we have emotions in the description, we are better able to account for aspects of distrust in science. Notably, it helps us explain some of the strange evidential weightings we sometimes see people making (4.2.1), and it helps us explain the stickiness of distrust - that is, the difficulty of re-establishing trust once lost (4.2.2.).

\subsubsection{Emotions, Bias and Evidential Weightings}

Jones (2019) notes that emotions have a biasing quality. That is, they lead us to weigh up evidence differently. Adrian Bardon (2020) makes the same point:

[W]e know that one's emotional state can affect how much attention is paid to aspects of a situation. A subject's feeling angry can result in greater attention being paid to evidence of blameworthiness; feeling fear can lead him to focus more on evidence of risk. Such changes can lead to different assessments of evidence, and thus to different conclusions (Bardon 2020, 17 - 18). 
The affective stew in which trust and distrust take place is no different. Engdahi and Lidskog (2012) describe this aspect of affective trust/distrust as: "Trust is an emotional attitude, a feeling that affects our judgments and makes us perceive the world (others as well as ourselves) in a specific way" (712).

Arpaly (2000) gestures toward the same phenomenon when she talks about people making "hot" and "cool" judgments (499). Hot judgments are those that are affectively laden and cooler judgments occur when there is less emotion involved. Interestingly, hot judgments need not be irrational. In one example from Arpaly, a woman decides in a feverish state of anxiety at 4:00am that she ought to leave her husband and this turns out to be exactly the right decision. There has also been extensive work on the epistemic productivity of anger anger can give you the energy to persist, and the focus to seek out very specific pieces of information (Srinivasan 2018, 126).

We see elements of this at work in the relationships between scientists and laypeople, which adds credibility to the idea that affect is a useful contribution to the discussion. Stephen John (2020), for instance, in his discussion of the vaccine hesitant parent described by Maya Goldenberg (2016), and some of his own previous work on vaccines (2011), takes the evidential weighting to be "peculiar" (John 2020, 58). On Goldenberg's description, parents and medics are talking passed each other because they have different values medics are worried about population level vaccine safety and parents are worried about the safety for their own particular children. What makes the parent's evidential weighting "peculiar" is that your child is just one amongst very many, why would you weigh the risk to them so much higher than the general population risk? John responds by appealing to values - you aren't willing to take on the risk for your own child no matter how small - thus defusing the evidential weighting problem (John 2020, 59). But we can also respond by pointing to emotional features of the interaction. You love your child, you may be anxious or frustrated or fearful in the medical setting, and the way you feel tilts the way that you see the evidence.

\subsubsection{The Stickiness of Distrust}

Directly linked to the point in 4.2 .1 is the "stickiness" of distrust, by which I mean the tendency of trust to be difficult to re-establish once lost. Distrust is difficult to shake off. Even when we are presented with evidence that distrust is no longer warranted and that trust should resume, this is difficult to do. For instance, if a lover betrays you, it may be difficult to re-establish trust, even if they present you with very compelling evidence that they are now trustworthy.

Sara Ahmed describes the "stickiness" of affect as follows: "Affect is what sticks, or what sustains, or preserves the connection between ideas, values and objects" (Ahmed 2010, 29). 
She uses this idea to explain what she calls "happy objects". That is, the way that particular objects acquire positive affect that persists over time. One example of a happy object is my partner's blue coffee mug, which he bought on holiday with his mother and he now insists on using for all of his hot drinks because it improves his mood. Objects can also be negatively affectively laden. I may have to pack my deceased cat's favourite blanket in the very back of the wardrobe because looking at it makes me too sad. Similarly, situations can also carry affect. Remember Fassin's description of South Africans reliving feelings of humiliation and fear in medical contexts because of the long history of abuse experienced in similar scenarios. Distrust is sticky - it is difficult to undo - because of the persistent negative emotions that link individuals to particular situations.

Karen Jones (2019) also identifies this sticky quality of distrust:

[A]s with other affective states, our trust and distrust can display recalcitrance; that is, they can be held in opposition to our judgments about trustworthiness and we can experience the nagging doubts and reluctance to rely characteristic of distrust even as we judge that the other is trustworthy (toward us, in the domain of issue) (Jones 2019, 960).

On Jones's account, the stickiness of distrust is linked to the biasing described in 4.3. The negative emotions connected to distrust lead us to add weight to evidence that supports our distrust, which in turn re-enforces distrust. Jones describes this as "affective looping" (Jones 2019, 961).

Including emotion in our account of trust in science, allows us to better account for this aspect of the phenomenon - the persistence of distrust - that we are already aware of. It also gestures towards what kinds of interventions are unlikely to be effective at improving public trust in science. Notably, just providing the public with information about why they should trust science is unlikely to achieve the desired effect in situations were negative affect is involved.

\section{Epistemic, Value-Based and Affective Trust in Science}

The descriptions of trust and distrust in science that have been discussed in this paper each point to important features of the phenomenon. Epistemic accounts provide us with a sense of when we should rationally trust or distrust science. Value-based accounts point to cases in which the values between the scientists and members of the public diverge, or when scientific values are opaque, undermining trust. Affective descriptions, such as discussed in this paper, indicate that individuals' pre-existing emotional states, or emotional states created by scientific intervention, can impact on individuals' ability and/or willingness to trust science. 
At the start of this paper, I said that all of these factors - epistemic, values, emotions - are important for our understanding distrust in science. But how do these different approaches relate to each other? In this section, I suggest that we think of the philosophical discussion about trust in science as analogous to philosophical discussions about objectivity in science, in which the term has multiple context-dependent meanings.

In the philosophical literature on scientific objectivity there has been a proliferation of descriptions of what "objectivity" is (Reiss and Sprenger 2017). Heather Douglas (2004) has identified eight meanings for process objectivity (one particular type of objectivity) alone, none of which are reduceable to each other. One reaction to this messy discussion space is to disregard the term entirely (Hacking 2015). Others have been concerned with maintaining the term, because of its important social function - notably, maintaining the trustworthiness of science (Burch and Furman 2019). Recent rescue strategies for objectivity have suggested that the term is multi-faceted and which meaning is relevant varies depending on context (Koskinen 2018, Burch and Furman, 2019).

This helps us better understand the state of the discussion of trust in science. Trust is multifaceted, involving epistemic, value-based, and affective elements. Which of these factors, or combination of factors, is relevant will vary depending on the agent and the position in which they find themselves in relation to science. It may be that the agent is lucky enough to find themselves consistently in situations where the epistemic considerations are clear and compelling, there is no divergence between the agent's own values and those employed in the relevant science, and they feel alright about the whole situation; in which case, trust is easily achieved and practically irrelevant. Other agents will find themselves in circumstances where one or more of these considerations are contested; they may not trust that the process by which the science was produced, they may think that they values employed in the production of that specific piece of science run counter to their own or are harmful to them, they may come from a community who has been on the receiving end of a long history of scientific abuse, and so current interactions with science are emotionally fraught. Which factor is salient will be context-specific, but they are all relevant for helping us understand the phenomenon.

\section{Conclusion}

Philosophers are very concerned about public trust and distrust in science, but their focus has been on epistemic and value-based considerations. In this paper I have argued that we need to pay attention to emotions. This allows us to better explain particular cases in which affect plays a role, such as South African HIV/AIDS treatment programmes in the early 2000s, and interventions in the recent West African Ebola outbreak. In both cases people needed the intervention, distrust prevented full public participation and limited their 
effectiveness. Including affect in our accounts helps us better understand persistent features of cases of scientific distrust, such as peculiar evidential weightings and the difficulty of undoing distrust once it has been lost. 


\section{Bibliography}

Ahmed, Sara. 2010. "Happy Objects." In The Affect Theory Reader, edited by Melissa Gregg and Gregory J Seigworth, 29-51. Durham and London: Duke University Press.

Anoko, Julienne. 2014. "Communication with Rebellious Communities during an Outbreak of Ebola VIrus in Guinea: An Anthropological Approach." Accessed March 8, 2020. http://www.ebola-anthropology.net/wpcontent/uploads/2014/12/Communicationduring-an-outbreak-of-Ebola-VirusDisease-with-rebellious-communities-in-Guinea.pdf.

Arpaly, Nomy. 2000. "On Acting Rationally against One's Best Judgment." Ethics 110 (3): 488-513.

-. 2004. Unprincipled Virtue: An Inquiry into Moral Agency. Oxford: Oxford University Press. Baier, Annette. 1986. "Trust and Antitrust." Ethics 96 (2) 231-260.

Bailey, Alison. 2018. "On Anger, Silence, and Epistemic Injustice" Royal Institute of Philosophy Supplements 84: 93 - 115.

Bardon, Adrian. 2020. The Truth About Denial: Bias and Self-Deception in Science, Politics, and Religion. Oxford: Oxford University Press.

Barrotta, Pierluigi, and Eleonora Montuschi . 2018. "The dam project: who are the experts?" In Science and Democracy: Controversies and Conflicts, by Barrotta, Pierluigi and Giovanni Scarafile, 17-34. Amsterdam: John Benjamins Publishing Company Biddle, Justin. 2018. "Antiscience Zealotry? Values, Epistemic Risk and the GMO Debate." Philosophy of Science 85: 360 - 379.

Brown, Matthew J. 2018. "Weaving Value Judgment into the Tapestry of Science." Philosophy, Theory, and Practice in Biology 10 (10) 1-8.

Burch, Matthew and Katherine Furman. 2019. "Objectivity in science and law: A shared rescue strategy." International Journal of Law and Psychiatry. 64: 60 -70.

Carman, Mary. 2020. "Moving between frustration and anger." Global Discourse (17) 215231.

De Melo-Martin, I, and K Intemann. 2018. The Fight Against Doubt: How to Bridge the Gap Between Scientists and the Public. Oxford: Oxford University Press.

Desclaux, Alice, Moustapha Diop, and Stéphane Doyon. 2017. "Fear and Containment: Contact Follow-up Perceptions and Social Effects in Senegal and Guinea." In The Politics of Fear: Médecins Sans Frontières and the West African Ebola Epidemic, by Michiel Hofman and Sokhieng Au, 209- 234. New York: Oxford University Press.

Douglas, Heather. 2004. "The irreducible Complexity of Objectivity." Synthese 138 (3) $453-$ 473.

Engdahl, Emma, and Rolf Lidskog. 2012. "Risk, communication and trust: Toward an emotional understanding of trust." Public Understanding of Science 23(6) 703 - 717.

Epstein, Steven. 1996. Impure Science: AIDS, Activism and the Politics of Knowlegde. California: University of California Press.

Espstein, Steven. 2007. Inclusion: The Politics of Difference in Medical Research. Chicago: University of Chicago Press.

Fairhead, James. 2016. "Understanding social resistance to Ebola Response in the forest region of the Republic of Guinea: an anthropological perspective." African Studies Review 59 (3) 7-31.

Fassin, Didier. 2007. When Bodies Remember: Experiences of AIDS in South Africa. California: University of California Press.

Faulkner, Paul. 2007. "On Telling and Trusting." Mind 116 (464) 875-902. 
Fine, Arthur. 1998. "The Viewpoint of No-one in Particular." Proceedings and Addresses of the American Philosophical Association 72 (2)9-28.

Goldenberg, Maya J. 2016. "Public Misunderstanding of Science? Reframing the Problem of Vaccine Hesitancy." Perspectives on Science 24 (4) 552-581.

Grasswick, Heidi E. 2010. "Scientific and lay communities: earning epistemic trust through knowledge sharing." Synthese 177 (3) 387-409.

Gumede, William. 2005. Thabo Mbeki and the Battle for the Soul of the ANC. Cape Town: Zebra Press.

Hacking, lan. 2015. "Let's not talk about objectivity." In Objectivity in Science: New

Perspectives from Science and Technology Studies, by Flavia Padovani, Alan RIchardson and Jonathan Y. Tsou ,19 -33. Springer New York.

Hawley, Katherine . 2019. How to be trustworthy . Oxford: Oxford University Press Holton, Richard, 1994. "Deciding to Trust, Coming to Believe.", Australasian Journal of Philosophy 72: 63- 76.

John, Stephen. 2017. "Epistemic trust and the ethics of science communication: against transparency, openness, sincerity and honesty." Social Epistemology 32 (2): 75-87.

John, Stephen. 2011. "Expert Testimony and Epistemological Free-Riding: The MMR Controversy." Philosophical Quarterly 244: 496-517.

John, Stepehn. 2020. "The Politics of Trust." In Trust: A Philosophical Approach, by Adriano Fabris, 49-61. Springer.

Jones, James H. 1981. Bad Blood: The Tuskegee Syphilis Experiment. New York: Free Press. Jones, Karen. 1995. "Trust as an Affective Attitude." Ethics 107 (1): 4- 25.

Jones, Karen.2004. "Trust and Terror." In Moral Psychology, by Peggy DesAutels and Margaret Urban Walker, 3-18. Lanham, MD: Rowman and Littlefield Jones, Karen. 2019. "Trust, distrust and affective looping." Ethics 176 (4): 955-968.

Jones, Ward E. 2002. "Dissident Versus Loyalist: Which Scientists Should We Trust?" The Journal of Value Inquiry (36) 511-520.

Kimmerer, Robin Wall. 2013. Braiding Sweetgrass: Indigenous Wisdom, Scientific Knowledge and the Teachings of Plants. United Kingdom: Penguin.

Kitcher, Philip. 2011. Science in Democratic Society. Prometheus Books.

Koskinen, Inkeri. 2018. "Defending a Risk Account of Scientific Objectivity." British Journal of Philosophy of Science 1-21.

Longino, Helen E. 1990. Science as Social Knowledge: Values and Objectivity in Scientific Inquiry. Princeton: Princeton University Press.

Nattrass, Nicoli. 2008. "AIDS and the Scientific Governance of Medicine in Post-Apartheid South Africa." African Affairs 107 (427) 157-176.

Oreskes, Naomi 2019. Why Trust Science? . Princeton: Princeton University Press.

Reiss, Julian, and Jan Sprenger. Winter 2017. "Scientific Objectivity." In Stanford Encyclopedia of Philosophy, by Edward N Zalta.

Scheman, Naomi. 2001. "Epistemology resuscitated." In Engineering Rationalities, by Nancy Tuana and Sandra Morgen, 23-52. Albany State: University of New York Press.

Srinivasan, Amia. 2018. "The Aptness of Anger." The Journal of Political Philosophy 26 (6): 123-144.

Steinberg, Jonny. 2009. Three Letter Plague: A Young Man's Journey Through a Great Epidemic. London: Vintage.

Steinberg, Jonny. 2016. "Re-examining the early years of anti-retroviral treatment in South Africa: A Taste for Medicine." African Affairs 116: 60 - 79. 
Strawson, Peter. 1962. "Freedom and Resentment."Proceedings of the British Academy 48:

$1-25$.

Thomas, Stephen B, and Sandra Crouse Quinn. 1991. "The Tuskegee Syphilis Study, 1932 1972: Implications for HIV and AIDS Risk Programs in the Black Community." American Journal of Public Health 81 (11): 1498- 1505.

Tsing, Anna. 2015. The Mushroom at the End of The World. Princeton: Princeton University Press.

Wilkinson, Annie, and James Fairhead. 2017. "Comparison of social resistance to Ebola response in Sierra Leone and Guinea suggest explanations lie in political configurations not culture." Critical Public Health 27 (1): 14 - 27.

World Health Organisation. 2016. Ebola Situation Repost - 2 March 2016. 